\title{
Influence of the diameter of nanoparticles in complexes metal- aquatic humic substances
}

\author{
Daniele Frasson Vieira $^{1+}$, , Nicolas Henrique Furquim ${ }^{1}{ }^{(\mathbb{D}}$, Wander Gustavo Botero ${ }^{2}$, Luciana Camargo de \\ Oliveira $^{3}$ (D), Danielle Goveia ${ }^{1}$ (D) \\ ${ }^{1}$ São Paulo State University “Júlio de Mesquita Filho” (UNESP), Experimental Campus of Itapeva, 519 Geraldo Alckmin St, Itapeva, São \\ Paulo, Brazil \\ ${ }^{2}$ Federal University of Alagoas (UFAL), Campus of Arapiraca, Manoel Severino Barbosa Av, Arapiraca, Alagoas, Brazil \\ ${ }^{3}$ Federal University of São Carlos (UFSCAR), Sorocaba Campus, João Leme dos Santos Hwy, Km 110 - SP-264, Sorocaba, São Paulo, Brazil
}

${ }^{+}$Corresponding author: Daniele Frasson Vieira, e-mail address: dani.frasson@hotmail.com

\section{ARTICLE INFO}

Article history:

Received: February 8, 2018

Accepted: May 24, 2018

Published: June 28, 2018
Keywords:
1. metal ions
2. nanoparticles
3. water systems
4. nanoparticle influence

\begin{abstract}
Nanoparticles are emerging as the object of research in all fields of chemistry, their special properties are matter for concern, because a considerable portion of these materials are eliminated in the environment. A key point of the discussion is how nanoparticles will interact with other components in natural waters. In this project, the main objective will be to study the interactions of nanoparticles with metallic ions in the presence of humic substances in environmental systems. It is intended to differentiate free and labile metal ions using nanoparticles and organic matter in the form of aquatic substances (extracted from samples collected on the coast of São Paulo). It is intended to simulate the environmental systems and to verify the competition between the complexants. The differentiation of the free and complexed ions will be done using an ultrafiltration system equipped with polyethersulfone membrane $(1 \mathrm{KDa})$ and determination of the metals by atomic absorption spectrometry with flame atomization.
\end{abstract}

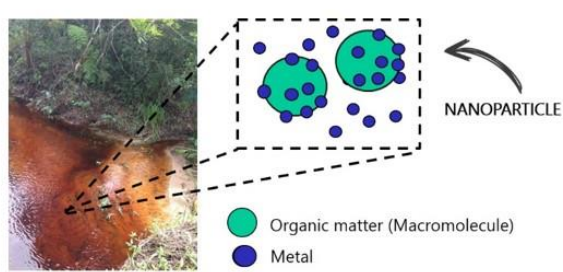

Metals can be found free (more toxic) or complexed with organic matter. Nanoparticles when discarded will interact with this system.

\section{Introduction}

By providing more efficient, lightweight, suitable and mainly low cost final products, many nanomaterials are in the commercialization stage. The increasing production and application of nanomaterials has provoked a wide discussion about the potential risks of these materials to the environment and to human health. Some studies suggest that, due to their small size, nanomaterials may have a greater permeability through the skin, mucous membranes and cell membranes, and may have their toxic effect exalted because they have a higher reactivity caused mainly by the increase of surface area ${ }^{1,2}$. As an example, gold, which is a practically inert metal but which in the form of nanoparticles becomes highly reactive ${ }^{3}$.

The properties of nanoparticles, which make them so valuable, are of concern in the analysis of the ecosystem since a significant portion will be eliminated in the environment. In this way, its chemical interactions, its cycle and destiny, are evolving into an important topic of discussion in all fields of chemistry. A key point of the discussion is how nanoparticles will interact with the other components in natural waters, such as 
metal ions, dissolved organic matter and microorganisms. In aquatic environments, organic matter exerts a great influence on the behavior of metals due to their physicochemical polyelectrolyte properties ${ }^{4}$.

Approximately $40 \%$ to $60 \%$ of the organic matter is in the form of Aquatic Humic Substances (SHA) that represent the main class of natural complexants present in natural waters. One study demonstrated that humic and fulvic acids can significantly alter the capacities and the mechanisms of adsorption of metals in silica nanoparticles. In this study, it was clear that humic material could increase the amount of metal bound to the nanoparticle, influencing the behavior of metals and nanoparticles in the environment ${ }^{5,6}$.

Only a small fraction of the total dissolved metal is present as free ions, most of which are in the form of stable complexes with dissolved inorganic or organic binders and organic particles ${ }^{7}$. Free metal ions are more toxic than complexed or adsorbed ions to some substance or surface of particles. So, the more strongly attached the less bioavailable and the lower the toxicity of the metal ${ }^{8}$.

In this system composed of metals, SHA and nanoparticles, there are two possibilities of action of the humic material: it can complex the metals and decrease the bioavailability and reactivity in a process of competition with the complexing sites of the nanoparticles, as well as interacting with the surface of the nanoparticle, increasing the absorption capacity of the metal and the ability to cross the cell wall carrying the metal into the cell, which translates into a greater toxicological risk to the environment. Thus, it becomes even more important to know the dynamic nature of the complexes $^{9,10}$. Our focus will be to understand the impact of silica nanoparticles on the matrix, that is, how they interfere in the speciation of iron and manganese metal ions in environmental systems, originally bound in organic matter.

\section{Experimental}

\subsection{Obtaining Aquatic Humic Substances}

In February 2017, approximately 100 liters of water samples were collected from the Juréia River, located in the city of São Sebastião-SP, due to the high content of organic matter present. After the collection, the extraction of the Aquatic Humic Substances was carried out. An adsorptive column chromatography system was mounted using the
DAX-8 superlite microporous resin which was suspended in deionized water and stored in a glass column, forming an exchanger bed. Then, by gravity, the samples were percolated through the glass column.

After saturation with SHA, as verified by the darkened color of the resin, a $0.1 \mathrm{~mol} \mathrm{~L}^{-1} \mathrm{NaOH}$ solution was used for the elution of SHA. The humic extract was collected at the base and taken to the oven and dried at a temperature of approximately $55^{\circ} \mathrm{C}$.

The in situ characterization of the source was carried out by means of determinations of $\mathrm{pH}$, temperature, dissolved oxygen and conductivity, from the calibration of the equipment, using reference standard solutions. The SHA were characterized by ultraviolet-visible spectrophotometry, where $2.0 \mathrm{mg}$ of dry SHA sample was dissolved in $10 \mathrm{~mL}$ of $0.05 \mathrm{~mol} \mathrm{~L}^{-1}$ $\mathrm{NaHCO}_{3}$ and the reading the absorbance of the sample on the Spectaphotrometer Specta 50 at wavelengths 465 and $665 \mathrm{~nm}$ to determine the $\mathrm{E} 4$ / E6 ratio based on the optical densities obtained at the respective wavelengths.

\subsection{Evaluation of metal-binder interactions}

The sample was digested to determine the concentration of the total metal and the free metal present in the water in natura. $300 \mathrm{~mL}$ of plate water was digested at approximately $120{ }^{\circ} \mathrm{C}$ using $10 \mathrm{ml}$ of nitric acid. The digest was quantitatively transferred to volumetric flask and the volume adjusted with deionized water to $50 \mathrm{~mL}$.

Subsequently, $250 \mathrm{~mL}$ solutions containing $\mathrm{Fe}$ and $\mathrm{Mn}$ ions were prepared in a concentration of approximately $2.0 \mathrm{mg} \mathrm{L}^{-1}$. The extracted SHA was added at a concentration of approximately $100 \mathrm{mg}$ $\mathrm{L}^{-1}$. These solutions were for the ultrafiltration system (Figure 1), using peristaltic pump, tygon tubes, $1 \mathrm{kDa}$ and $47 \mathrm{~mm}$ diameter porosity membrane (Ultracel Ultrafiltration Discs) and pressure controllers. 


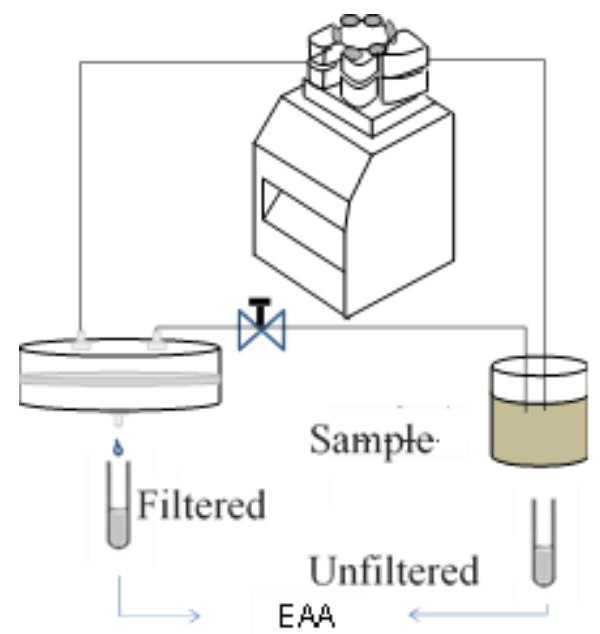

Figure 1. Ultrafiltration system used to evaluate complexes formed between metal ions and binders (chemicals and nanoparticles).
After passing through the $1 \mathrm{kDa}$ membrane, an aliquot (time zero) was withdrawn. The metal determined in this aliquot is the free metal and the metal complexed to the fraction of organic matter $<1 \mathrm{kDa}$. Considering that this fraction of organic matter is very small in relation to the fraction> $1 \mathrm{kDa}$ and to facilitate the understanding, we will consider this aliquot as free metal. LUDOX silica nanoparticles were then added. LUDOX silica nanoparticles are sold commercially for equipment calibration, so they have specific and regular sizes and are in suspension form in water. Three suspensions were chosen for analysis: LUDOX LS30, LUDOX TM40 and LUDOX TM50. These nanoparticles used in these experiments were characterized in earlier studies (Table 1$)^{9}$. Were added to the solutions $800 \mu \mathrm{L}$ of LS30, $1070 \mu \mathrm{L}$ of TM40 and $1330 \mu \mathrm{L}$ of TM50 all in the proportion in moles of $1: 1$.

Table 1. Characterization of silica nanoparticles in different sizes.

\begin{tabular}{cccc}
\hline Type of silica & Diameter $(\mathbf{n m})$ & Surface $\mathbf{a r e a}\left(\mathbf{m}^{2} / \mathbf{g}_{\text {silica }}\right)$ & Number of $\mathbf{p a r t i c l e s} / \mathbf{g}_{\text {silica }}$ \\
\hline LS30 & 8 & 215 & $3.86 \mathrm{E}+17$ \\
TM40 & 17 & 140 & $3.74 \mathrm{E}+16$ \\
TM50 & 31 & 140 & $5.73 \mathrm{E}+15$ \\
\hline
\end{tabular}

The filtrate aliquots were withdrawn from time to time for $24 \mathrm{~h}$ and the metal determinations were made by flame atomization atomic absorption spectrometer (novAA 400 Analytik Jena), following the manufacturer's recommendations.

\section{Results and Discussion}

Table 2. Preliminary characterizations of water samples collected in the tributary of Juréia River in February/2017.

\begin{tabular}{ccc}
\hline Parameters analyzed & $\begin{array}{c}\text { Sample of water from Juréia } \\
\text { River }\end{array}$ & $\begin{array}{c}\text { Sample of water from } \\
\text { the Itapanhaú River } \\
{[\mathbf{1 1}]}\end{array}$ \\
\hline $\mathrm{pH}$ & 5.38 & 5.20 \\
Temperature $\left({ }^{\circ} \mathrm{C}\right)$ & 27.00 & 22.20 \\
Conductivity $\left(\mu \mathrm{S} \mathrm{cm}^{-1}\right)$ & 60.30 & 73.20 \\
Dissolved oxygen $\left(\mathrm{mg} \mathrm{L}^{-1}\right)$ & 5.20 & 3.70 \\
\hline
\end{tabular}

The National Environmental Council (CONAMA) in Resolution No. 357, dated March $17,2005^{12}$ classifies the water bodies and environmental guidelines for its setting and establishes the conditions and standards for effluent releases, and makes other provisions from of parameters. Analyzing the dissolved oxygen
Considering that the SHA structure is directly related to its origin, it is necessary to carry out the preliminary characterization of the environment where the samples were collected. The results of the in situ characterization are shown in Table 2. parameter, the water sample can be classified as class 2 , since the concentration is greater than 5 $\mathrm{mg} \mathrm{L}^{-1}$ and less than $6 \mathrm{mg} \mathrm{L}^{-1}$. However, the $\mathrm{pH}$ presented a value below the ideal considered according to CONAMA (pH of 6.0 to 9.0 ), but the value obtained is characteristic of water bodies rich in organic matter. The results presented 
similarities with rich source of organic matter evaluated in previous studies, as can be observed in Table 2.

The absorbance values found in UV-VIS spectrophotometry at wavelengths 465 and $665 \mathrm{~nm}$, respectively, were 0.02753 and 0.0268 . Therefore, the ratio of E4/E6 is equal to 1.027. This ratio indicates how high is the degree of condensation of the sample, that is, if the obtained value of the ratio decreases, the sample shows a high degree of structural condensation, being associated directly to the degree of humification. If the values obtained are high, it indicates a less condensed structure and, consequently, a lower degree of humification ${ }^{13}$. In this case we can infer that SHA does not present such a high degree of structural condensation, considering high values less than 1.0

Table 3 presents the result of the determination of the total metal present in the water in natura, considering all the metal detected in the sample after the acid digestion. The free metal is that obtained in the membrane filtered solution of $1 \mathrm{kDa}$.

Table 3. Total metal concentration in the Juréia River in natura and concentration of free metal.

\begin{tabular}{ccc}
\hline \multicolumn{3}{c}{ Concentration of metals } \\
\hline & $\mathbf{F e}\left(\mathbf{m g ~ L ~ L}^{\mathbf{- 1}}\right)$ & $\mathbf{M n}\left(\mathbf{m g ~ L}^{\mathbf{- 1}}\right)$ \\
\cline { 2 - 3 } Total & 37.20 & 2.70 \\
Free & 0.20 & 0.20 \\
\hline
\end{tabular}

Comparing the concentrations of free iron with the in natura concentration, it is verified that the iron present in the organic matter is almost totally forming Fe-SHA complexes. With the manganese the same behavior is observed, but to a lesser extent, considering the amount of this metal in the well.

After the differentiation of the free and complexed metals to SHA and addition of the silica nanoparticles, the concentration of the free metals was evaluated from time to time until $24 \mathrm{~h}$. The impact that the nanoparticles could cause on the complexes formed was evaluated by varying the size of the nanoparticle. Tables 4, 5 and 6 show the values obtained for the metal concentrations complexed with the SHA> $1 \mathrm{kDa}$, and the free metal quantified in the filtrate (SHA fraction $<1 \mathrm{kDa})$.

Table 4. Fractionation of the complexed metal ions to the Aquatic Humic Substances. Complexation time: $24 \mathrm{~h}$ after addition of LUDOX LS30\% nanoparticle (8 $\mathrm{nm}$ in diameter).

\begin{tabular}{|c|c|c|c|}
\hline Organic Matter & 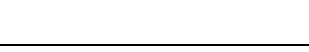 & $\mathrm{Fe}\left(\mathrm{mg} \mathrm{L} \mathrm{L}^{-1}\right)$ & $\operatorname{Mn}\left(m g L^{-1}\right)$ \\
\hline \multirow{3}{*}{ SHA-Juréia } & Total metal & 1.7 & 2.2 \\
\hline & Free metal & 0.8 & 1.0 \\
\hline & LUDOX LS30\% & 1.3 & 0.5 \\
\hline
\end{tabular}

Table 5. Fractionation of the complexed metal ions to the Aquatic Humic Substances. Complexation time: $24 \mathrm{~h}$ after addition of the LUDOX TM40\% nanoparticle (17 $\mathrm{nm}$ diameter).

\begin{tabular}{|c|c|c|c|}
\hline Organic Matter & & $\mathrm{Fe}\left(\mathrm{mg} \mathrm{L}^{-1}\right)$ & $\operatorname{Mn}\left(\mathrm{mg} \mathrm{L}^{-1}\right)$ \\
\hline \multirow{3}{*}{ SHA-Juréia } & Total metal & 1.8 & 1.9 \\
\hline & Free metal & 0.3 & 0.4 \\
\hline & LUDOX TM40\% & 0.2 & 0.3 \\
\hline
\end{tabular}


Table 6. Fractionation of the complexed metal ions to the Aquatic Humic Substances. Complexation time: $24 \mathrm{~h}$ after addition of LUDOX TM50\% nanoparticle (31 nm diameter).

\begin{tabular}{crr}
\hline Organic Matter & & Fe (mg L \\
\hline & Total metal & 1.8 \\
SHA-Juréia & Free metal & 0.2 \\
& LUDOX TM50\% & 0.2 \\
\hline
\end{tabular}

It was possible to observe that the size of the nanoparticle and the surface area alter the stability of the SHA-Metal complexes. The LUDOX LS30 nanoparticle has a smaller diameter and, consequently, a larger surface area. When added to the solution increases the proportion of free metal, providing the labile metal, which is interacting weakly with the organic matter. By evaluating the data presented by the addition of the larger nanoparticles (TM40 and TM50) it was verified that the amount of free metal does not change. There are two strands here, one of which indicates that the larger diameter nanoparticle does not interfere with the formation of the SHAMetal complexes, that is, it does not increase the bioavailability of the labile metal. Another possibility, which cannot be evaluated by studying only the free metal, is the stability of the nanoparticle-Metal complexes.

The kinetics of the reaction were evaluated by time and the results quantified in the aliquots were plotted in the subsequent figures. Figure 2 shows the behavior of the free iron concentration over a period of $24 \mathrm{~h}$ of complexation in the presence of nanoparticles of different diameters, showing its influence on the Fe-SHA complexes for SHA extracted from the Juréia River.

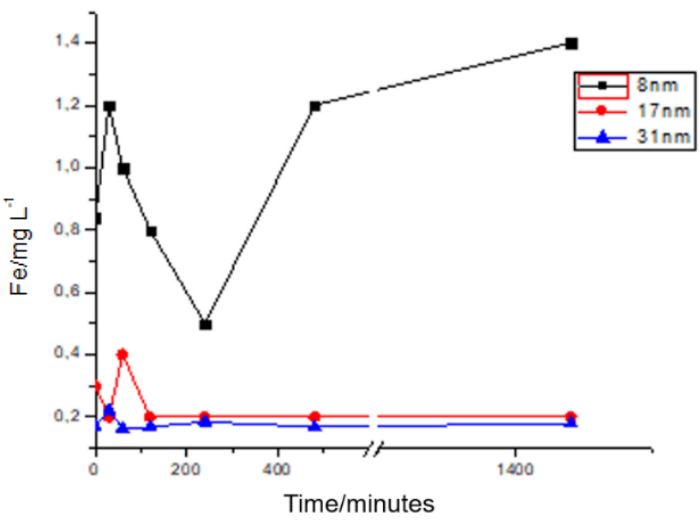

Figure 2. Free iron determined in the filtrate after addition of LUDOX LS30 $(8 \mathrm{~nm})$, TM40 (17 nm) and TM50 (31 nm) nanoparticles to the Metal-SHA complex, SHA extracted from the Juréia River.
It is worth mentioning that time zero corresponds to the moment before the addition of the silica nanoparticles. It is noted that in the first minutes after the addition of LUDOX LS30\% silica nanoparticle, an increase in free iron concentration occurs. Probably the ions originally complexed to SHA may be available in solution, breaking the interaction between the formed complex (SHA metal) by influence of the nanoparticle. SHA may also be interacting with the nanoparticle, masking the complexing sites and thus leaving the metals available. In the sequence a considerable drop occurs in this concentration, showing that the free iron ions are complexing with the nanoparticles and / or SHA. As after a longer time, the concentration of free ions returns to increase, we can infer that the metal-SHA interaction is stronger than the metalnanoparticle interaction.

Observing the behavior of the concentration of free iron ions after the addition of the nanoparticles of silica TM40\% and TM50\%, it is observed that it remained practically constant throughout the time. This indicates that the metalSHA complex is not influenced by these nanoparticles. Figure 3 shows the results of the concentration of free manganese in $24 \mathrm{~h}$ of complexation, showing the influence of the nanoparticles in the Mn-SHA complexes for SHA extracted from the Juréia River.

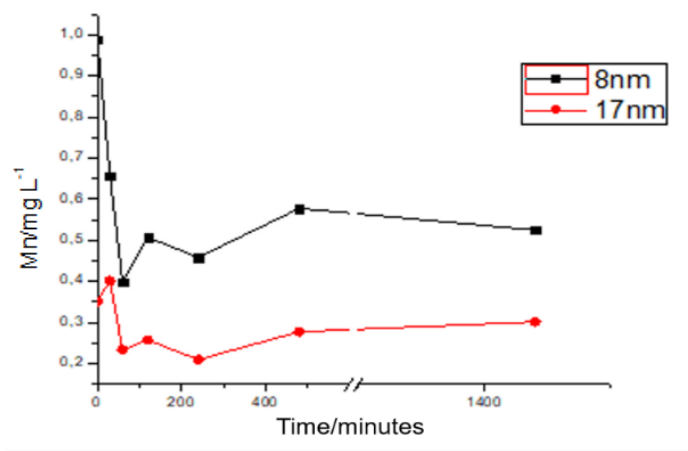

Figure 3. Free Mn determined in the filtrate after addition of the LUDOX LS30 (8 nm) and TM40 $(17 \mathrm{~nm})$ nanoparticles to the Metal-SHA complex, SHA extracted from the Juréia River. 
In the presence of LUDOX LS30\%, in the first minutes the concentration of Mn falls, possibly the free ions formed complexes with the nanoparticle. However, after $120 \mathrm{~min}$, there is a small increase and subsequent stabilization of the concentration of free ions. In the presence of LUDOX TM40\%, it is verified that in the first minutes after the addition of the nanoparticle nothing happens, the value of the concentration is the same as in time zero. In the sequence, it presents the same behavior observed with the LS30, that is, a drop of free manganese ions and then small variations.

More information is needed to make sure the ion is complexing with the nanoparticle or SHA. This doubt can be evidenced when we change the binder addition sequence, that is, when we add SHA to the stable complexes M-nanoparticles.

\section{Conclusion}

The results obtained so far have shown to be promising in relation to the impact of the nanoparticles on the environment, indicating that the size and surface area interfere with the behavior and availability of the metals in the environment, and the lower the nano-silica, the higher the metal complex, complexed prior to SHA.

\section{References}

[1] Zanetti-Ramos, B. G., Creczynski-Pasa, T. B., $\mathrm{O}$ desenvolvimento da nanotecnologia: cenário mundial e nacional de investimentos, Rev. Bras. Farm. 89 (2) (2008) 95-101.

[2] Contreras, J. E., Rodríguez, E. A., Nanostructured insulators - A review of nanotechnology concepts for outdoor ceramic insulators, Ceramics International, México 43 (12) (2017) $8545-8550$. https://doi.org/10.1016/j.ceramint.2017.04.105.

[3] Paschoalino, M. P., Marcone, G. P. S., Gardim, W. F., Nanomaterials and the environmental issue, Quím. Nova 33 (2) (2010) 421-430. https://doi.org/10.1590/S0100-

40422010000200033 .

[4] Botero, W. G., Humic substances: interactions with nutrients and contaminants, 2010. 95 f. Thesis (Doctorate) - Course of Chemistry, Institute of Chemistry of Araraquara, São Paulo State University, Araraquara, SP, 2010.
[5] Liang, L., Lv, J., Luo, L., Zhang, J., Zhang, S., Influences of surface-coated fulvic and humic acids on the adsorption of metal cations to $\mathrm{SiO}_{2}$ nanoparticles, Colloids and Surfaces A: Physicochemical and Engineering Aspects 389 (13) (2011) 27-32. https://doi.org/10.1016/j.colsurfa.2011.09.002.

[6] Liang, L., Luo L., Zhang S., Adsorption and desorption of humic and fulvic acids on $\mathrm{SiO}_{2}$ particles at nano and micro-scales, Colloids and Surfaces A: Physicochemical and Engineering Aspects $\quad 384 \quad(1-3) \quad$ (2011) 126-130. https://doi.org/10.1016/j.colsurfa.2011.03.045.

[7] Batley, G. E., Trace elements speciation: Analytical methods and problems, G. E. Batley Ed., CRC Press, Boca Raton, FL, 1989.

[8] Bayen, S., Gunkel-Grillon, P., Worms, I., Martin, M., Buffle, J., Influence of inorganic complexes on the transport of trace metals through permeation liquid membrane, Analytica Chimica $\begin{array}{llll}\text { Acta } & 646 \quad(1-2) \quad \text { (2009) 104-110. }\end{array}$ https://doi.org/10.1016/j.aca.2009.04.040.

[9] Goveia, D., Pinheiro, J. P., Milkova, V., Rosa, A. H., van Leeuwen, H. P., Dynamics and Heterogeneity of $\mathrm{Pb}(\mathrm{II})$ Binding by $\mathrm{SiO}_{2}$ Nanoparticles in an Aqueous Dispersion, Langmuir $27 \quad$ (12) (2011) 7877-7883. https://doi.org/10.1021/1a2008182.

[10] Goveia, D., Lobo, F. A., Burba, P., Fraceto, L. F., Dias-Filho, N. L., Rosa, A. H., Aproach combining online metal exchange and tangentialflow ultrafiltration for an in situ characterization of metal species in humic hydrocolloids, Analytical and Bioanalytical Chemistry 397 (2010) 851-860. https://doi.org/10.1007/s00216010-3547-5.

[11] Goveia, D., Rocha, J. C., Camargo de Oliveira, L., Cardoso de Morais, L., Campos, V. de, Fernando Fracetto, L., Rosa, A. H., Structural characterization of the humic substances extracted from the Itapanhaú and Iguape rivers, Quim. Nova $34 \quad$ (5) (2011) 753-758. https://doi.org/10.1590/S010040422011000500005 .

[12] BRAZIL. Ministry of the Environment, National Environment Council, CONAMA. 
CONAMA Resolution No. 357 of March 17, 2005 - In: Resolutions, 2005.

[13] Rosa, L. M. T., Humina as environmental remedy: influence of extraction in the retention of potentially toxic metals, 2017. $83 \mathrm{f}$. Dissertation (Master degree) - Course of Biotechnology and Environmental Monitoring, Federal University of São Carlos, Sorocaba, SP, 2017. 